\title{
Applications of Machine Learning and Service Oriented Architectures for the New Era of Smart Living
}

\author{
Sofoklis Kyriazakos ${ }^{1}$, George Labropoulos ${ }^{1}$, Nikos Zonidis ${ }^{1}$, \\ Magda Foti ${ }^{1}$ and Albena Mihovska ${ }^{2}$ \\ Converge ICT Solutions \& Services S.A., 74, Panormou str., \\ 11523 Athens, Greece \\ CTIF, Aalborg University, Frederik Bajersvejx 7C,9220 Aalborg, Denmark
}

Received 28 May 2014; Accepted 28 June 2014

Publication 31 August 2014

\begin{abstract}
In this paper we present a the application of advanced pattern matching algorithms and the utilization of a cloud-based Service Oriented Architecture (SOA) to offer a number of rich personalized applications for Ambient Living, through a novel Building Management System (BMS). The novelty presented in this paper is deriving from the evolution of a proprietary BMS product, namely Ecosystem, which is enhanced with the features presented in this paper, to address high demand for personalization and service adaptation in the new era of Information and Communication Technologies.
\end{abstract}

Keywords: Ecosystem; CBR; machine learning; SOA; service elements.

\section{Introduction}

BMS platforms in the market today are strongly linked with industrial control hardware, meant for machinery with tight schedules, requirements, and specific operating parameters. However, people in homes and businesses have constantly varying schedules and requirements, their equipment and wiring

Journal of Communication, Navigation, Sensing and Services, Vol. 1, 181-196.

doi: 10.13052/jconasense2246-2120.124

(C) 2014 River Publishers. All rights reserved. 